\title{
KNOWLEDGE MANAGEMENT FOR LEARNING MANAGEMENT SYSTEM MENGGUNAKAN BALANCE SCORECARD DAN CRITICAL SUCCES FACTOR
}

\author{
Reko Syarif Hidayatullah ${ }^{1}$, Dewi Mustari ${ }^{2}$ \\ ${ }^{1.2}$ Teknik Informatika, Fakultas Teknik dan Ilmu Komputer, Universitas Indraprasta PGRI \\ ${ }^{1}$ rifkyjr@yahoo.co.id, ${ }^{2}$ mustaridewi@yahoo.com
}

\begin{abstract}
Technology that is increasingly developing will create a life journey to the digital world. Currently, information technology is very helpful in daily work from the lower class to the top. They can use information technology to get the information needed. Currently X University is developing a distance learning process using the Learning Management system information system as a result of the outbreak that is currently hitting this country, of course, lectures are currently being stopped. And learning is done by oline. Of course, currently online learning can be done using a variety of existing applications, but it certainly has shortcomings in data management when using common applications. Therefore university $x$ developed an online learning system using a Learning Management System (LMS) to make it easier for university $x$ to monitor online learning activities. So that everything can be realized properly, an assessment strategy is made based on existing problems by getting solutions from SWOT analysis, Balanced Scorecard and also Critical Success factors to assess what needs are needed so that the use of LMS can be successful by using Knowledge Management.
\end{abstract}

Keywords: SWOT, Balanced Scorecard, Critical Success Factor

\begin{abstract}
Abstrak
Teknologi yang semakin hari semakin berkembang akan menciptakan sebuah perjalanan hidup menuju dunia digital. Saat ini teknologi informasi sangat membantu dalam pekerjaan sehari dari kalangan bawah samapai atas sudah bisa memanfaatkan teknolgi informasi untuk mendapatkan informasi yang di butuhkan. Saat ini Universitas $\mathrm{x}$ sedang mengembakan proses pembelajaran jarak jauh dengan menggunakan sistem informasi Learning Management system sebagai dapat dari wabah yang sedang melanda negeri ini tentunya perkuliahan saat ini d hentikan. Dan pembelajaran dilakukan dengan oline. Tentu saja saat ini pembelajaran online bisa d lakukan dengan menggunakan berbagai macam aplikasi yang ada, akan tetapi pastinya memiliki kekurangan dalam manajeman data jika menggunakan aplikasi yang umum. Oleh sebab itu universitas x mengembangkan sistem belajar online menggunakan Learning Management System (LMS) untuk mempermudah universitas x dalam memonitor kegiatan pembelajaran online. Agar semua bisa terealisasi dengan baik maka dibuat strategy penilaian berdasarkan masalah yang ada dengan mendapatkan solusi dari analisis SWOT, Balanced Scorecard dan juga Critical Success factor untuk menilai kebutuha apa saja yang diperlukan agar penggunaan LMS bisa success dengan menggunakan Knowledge Management.
\end{abstract}

Kata kunci: SWOT, Balanced Scorecard, Faktor Sukses Kritis 


\section{Pendahuluan}

Teknologi informasi semakin hari semakin berkembang, seiring dengan kemjauan sistem informasi maka pengaksesan terhadap data ataupun informasi dapat berlangsung secara cepat, efisien dan akurat [6]. Universitas X Jakarta merupakan salah satu perguruan tinggi yang sedang berkembang terutama untuk Jurusan Informatika. Untuk menunjang perkembangan universitas menggunakan sistem informasi yang membantu pengelolaan informasi yang ada. Universitas menggunakan sistem informasi sebagai usaha untuk meningkatkan kualitas pelayanan kepada mahasiswa, dosen, dan karyawan yang membantu dalam terlaksananya kegiatan pengajaran. Terutama saat ini sedang terjadi yang namanya wabah penyakit yang disebut dengan Covid 19, sehingga mendorong Universitas $\mathrm{X}$ untuk mengembangkan sistem informasi akademik. Kenapa harus mengembangkan sistem informasi tersebut, jawabannya adalah saat ini dengan adanya covid 19 adanya penghentian pembelajaran di dalam kelas untuk mengurangi terjadinya penularan penyakit. Oleh sebab itu, mau tidak mau Universitas harus menemukan solusi bagaimana caranya agar mahasiswa, dosen masih bisa terus melakukan pengajaran secara online. Dengan membuat sebuah sistem yang bisa membantu mahasiswa, dosen dan karyawan dalam melaksanakan tugas masing-masing, itu semua merupakan pekerjaan rumah yang sangat berat karena darurat.Selain itu, Universitas memiliki mitra kerjasama dalam meningkatkan pelayanan pendidkan baik itu dalam negeri maupun luar negeri. Untuk meningkatkan pelayanan dan bisnis manajemen SI yang baik merupakan faktor penting yang harus diperhatikan. Dengan adanya manajemen sistem informasi yang baik dapat meningkatkan daya saing yang akan menjadi nilai plus dalam persaingan bisnis serta akan meningkatkan daya saing yang berkelanjutan [3]. Pearce dan Robinson [9] bahwa manajemen strategis adalah sebagai suatu rangkaian keputusan dan tindakan yang menghasilkan formulasi danimplementasi rencana untuk mencapai tujuan perusahaan. Dengan hal tersebut Universitas $\mathrm{x}$ tentunya memerlukan Strategic Planning for Information System untuk menunjang daya saing dan mengembangkan bisnisnya [1]. Untuk mendukung analisis yang baik maka digunakan sebuah alat ukur kinerja SI yaitu Balance Scorecard. Balance Scorecard (BSC) merupakan suatu kerangka kerja baru yang mengintegrasikan berbagai ukuran yang diturunkan dari strategi organisasi [2]. Menurut Debowski [10], Technology merupakan peran pendukung yang penting dalam Knowledge Management, dimana dibutuhkan user yang berkompeten dan confident ketika menggunakannya. Dari uraian permasalahan yang ada maka didapat identifikasi permasalahan yaitu Bagaimana membangun strategic planning for information system yang mampu beradaptasi dan selaras dengan Strategi Bisnis [4] Universitas x, sehingga dengan demikian visi, misi dan tujuan dapat tercapai. Knowledge dibagi menjadi dua jenis yaitu Explicit knowledge dan Tacit Knowledge, yang dapat dijabarkan sebagai berikut:

a. Explicit Knowledge adalah sesuatu yang dapat diekspresikan dengan kata-kata dan angka, serta dapat disampaikan dalam bentuk ilmiah, spesifikasi, manual dan sebagainya. Knowledge jenis ini dapat segera diteruskan dari satu individu ke individu lainnya secara formal dan sistematis. Explicit knowledge juga dapat dijelaskan sebagai suatu proses, metoda, cara, pola bisnis dan pengalaman desain dari suatu produksi. b. Tacit Knowledge adalah knowledge dari para pakar, baik individu maupun masyarakat, serta pengalaman mereka. Tacit knowledge bersifat sangat personal dan sulit dirumuskan sehingga membuatnya sangat sulit untuk dikomunikasikan atau disampaikan kepada orang lain. Perasaan pribadi, intuisi, bahasa tubuh, pengalaman fisik serta petunjuk praktis (ruleof-thumb) termasuk dalam jenis tacit knowledge. Manajemen strategis merupakan rangkaian dua perkataan dari kata "manajemen dan strategi" yang masing-masing memiliki satu terminologi berubah dengan memiliki pengertian tersendiri pula. Menurut Holt (Winardi) sebagai berikut: "Management is the process of planning, organizing, leading, and controling that encompasses human, material, financial and information resourcess is an organizational envirounment". Perencanaan strategis sistem teknologi informasi mempunyai tahapantahapan sebagai berikut:

a. Analisis Eksternal

b. SWOT Strategy

c. Analisis Internal

Perangkat lunak sebagai salah satu komponen TI, yang digunakan berkaitan dengan aktivitas atau Proses Bisnis suatu organisasi disebut aplikasi[2].

\begin{tabular}{|c|c|}
\hline STRATEGIC & HIGH POTENTIAL \\
\hline $\begin{array}{l}\text { Aplikasi yang sangat penting } \\
\text { untuk mempertahankan } \\
\text { strategi bisnis masa depan } \\
\text { Application on which the } \\
\text { organization currently } \\
\text { depends for success }\end{array}$ & $\begin{array}{l}\text { Aplikasi yang mungkin penting } \\
\text { dalam mencapai keberhasilan } \\
\text { di masa mendatang } \\
\text { Application that are valuable } \\
\text { but not critical to success }\end{array}$ \\
\hline KEY OPERATIONAL & SUPPORT \\
\hline
\end{tabular}

Gambar 1 Matriks Portofolio Aplikasi [2]

Vitale mengklasifikasikan metodologi perencanaan strategi SI menjadi alignment dan impact. Keduanya berbeda dalam hal tujuan akhir. Alignment bertujuan mendukung tujuan bisnis, sedangkan impact mendukung keunggulan daya saing. Untuk menganalisis kekuatan dan kelemahan, serta peluang dan ancaman terhadap organisasi kemudian dilakukan analisis SWOT. Hasil analisis ini akan menunjukkan posisi organisasi dalam lingkungan bisnis yang bersangkutan. Dalam proses perumusan strategi tersebut di atas digunakan dua macam alat 
bantu yaitu Balanced Scorecard (BSC) dan Critical Success Factor (CSF). BSC adalah alat bantu manajemen yang sangat populer, dikembangkan oleh Kaplan dan Newton dari Harvard Businesss School [2].

\begin{tabular}{ccc}
\hline STRATEGIC & \multicolumn{1}{c}{ HIGH POTENTIAL } \\
(STARTS) & \multicolumn{1}{c}{ (WILDCATS) } \\
\hline$\checkmark$ inovasi terus menerus & $\checkmark$ Proses penelitian dan desain \\
$\checkmark$ integrasi vertikal & $\checkmark$ minimal integrasi \\
$\checkmark$ Bernilai tambah tinggi & $\checkmark$ pengendalian biaya \\
$\checkmark$ Defensive inovasi & $\checkmark$ Defensif / rasionalisasi \\
$\checkmark$ Pemenfaatan sumber & $\checkmark$ Efisiensi \\
$\begin{array}{c}\text { daya yang efektif } \\
\text { Kualitas tinggi }\end{array}$ & $\checkmark$ Sustained quality \\
\hline KEY OPERATIONAL & \multicolumn{2}{c}{ SUPPORT (DOGS) } \\
(CASH COWS) & \\
\hline
\end{tabular}

Gambar 2 Peran Portofolio Aplikasi [2]

BSC dan CSF merupakan cara yang sangat efektif untuk meyakinkan bahwa terjadi pemaduan strategis antara strategi SI Dalam perkembangannya BSC lebih dimanfaatkan sebagai alat yang efektif untuk perencanaan strategis, yaitu sebagai alat untuk menterjemahkan misi, visi, peran kunci, faktor penentu keberhasilan, tujuan, tolok ukur dan target kinerja serta tindakan perbaikan yang komprehensip, koheren, terukur dan berimbang. Ukuran yang relevan dan sering disebut key performance index (KPI). BSC mengidentifikasi kebutuhan SI untuk mengukur kinerja pencapaian sasaran bisnis. Analisis CSF (Critical Success Factor) mengidentifikasi apa yang harus dikerjakan atau diubah agar sasaran bisnis tercapai[2]. Kombinasi dengan Strategi Bisnis organisasi. Peter Gottschalk [9] mendefinisikan knowledge management sebagai metode untuk mensimplifikasi dan meningkatkan proses membagi, mendistribusi, mencipatakan, menagkap dan memahami knowledge di dalam perusahaan.

Komponen kritis knowledge yang dibutuhkan dalam pelaksanaan strategi KM yang berhasil adalah sebagai berikut [5]:

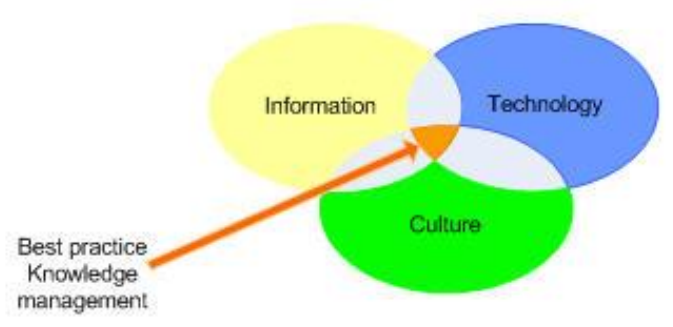

Gambar 3 Knowledge Management yang sukses [5]

Balance Scorecard adalah sistem penilaian kinerja yang menunjang kelangsungan hidup dan sustainability of growth organisasi. Balance Scorecard merupakan sistem penilaian kinerja yang dikembangkan berdasarkan strategi organisasi. Balance Scorecard yaitu sistem penilaian kinerja yang mengintegrasikan aspek finansial dengan aspek lain yang penting bagi organisasi.

\section{Metode Penelitian}

Metode yang digunakan dalam penelitian ini adalah studi pustaka dari berbagai kasus dalam Jurnal yang membahas bagaimana membuat strategic planning for information system dan juga bagaimana memetakan strategi manajemen dengan menggunakan Balanced Scorecard pada sebuah institusi sehingga mengahasilkan analisis deskriptif. Dan pendekatan pada penelitian ini adalah pendekatam secara general empiris berdasarkan pengalaman dan teori-teori yang berkaitan dengan metode strategic management for information system dan Strategi manejeman dengan menggunakan Balanced Scorecard.

\section{Hasil dan Pembahasan}

a. Analisis Kompetitif Universitas $\mathrm{x}$

Lingkungan operasional memiliki pengaruh yang bersar terhadap persaingan. Bukan hanya masalah persaingan saja, dalam keadaan darurat nasional karna wabah yang sedang melanda negeri ini. Tentunya, Universitas harus meningkatkan kualitas sistem informasi yang akan menentukan kelangsungan dari Universitas x. dengan adanya wabah covid 19 ini banyak usaha yang gulung tikar termasuk Universitas yang akan sangat kesulitan mendapatkan mahasiswa terutama untuk universitas swasta. Bahkan mahasiswa yang sudah adapun banyak yang mengundurkan diri karena tidak bisa membayar administrasi. Oleh karena itu banyak sekali pekerjaan rumah yang harus di selesaikan sebagai dampak dari wabah tersebut salah satunya sistem informasi akademik yang akan menentukan bagaimana sistem tersebut berjalan dengan baik untuk bisa melayani mahasiswa, dosen dan karyawan. Langkah pertama yaitu menganalisis menggunakan model kompetitif portr untuk memahasi dan mengevaluasi struktur lingkungan dan ancaman dalam suatu jenis usaha. Model tersebut menjelaskan ada lima kekuatan untuk menentukan ketertarikan dan keuantungan dari sebuah industry yaitu [5]:

1) Pesaing dalam industri yang sama (Intraindustry rivalry),

2) Kekuatan dari para konsumen (The bargaining power of buyers),

3) Kekuatan dari para pemasok (The bargaining power od suppliers),

4) Ancaman dari pesaing baru (The threat of new entrants),

5) Ancaman dari pendukung produk atau layanan (The threat of substitute product or service). 


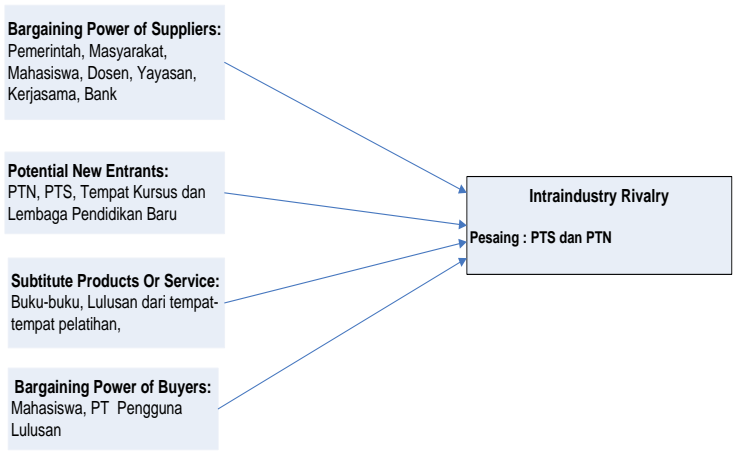

Gambar 4 dari analisis kompetitif Universitas X

\section{b.Analisis SWOT}

Strategi manajemen yang akan diterapkan pada Universitas $\mathrm{x}$ akan menggunakan alat SWOT yang digambarkan dalam matriks SWOT sebagai berikut:

Tabel 1 Analisis SWOT

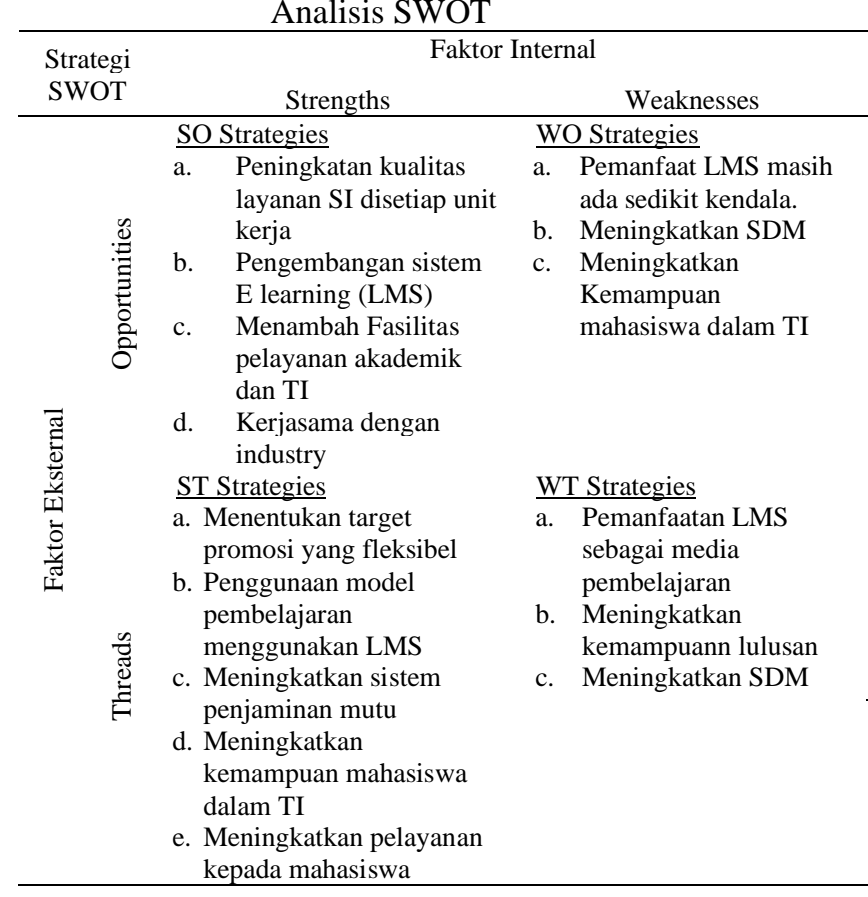

c. Analisis Balanced Scorecard dan critical success factor

Penguraian dari objektifitas perusahaan akan di dasarkan pada strategi strategy theme dan analisis matrik SWOT. Dimana hasil dari analisis SWOT akan dipetakan ke masing-masing perspektif yang ada. Strategy pada perspektif balanced scorecard pada kampus $\mathrm{x}$ adalah sebagai berikut: konsolidasi Balanced Scorecard dan Analisis

Critical Succes Factor Perspektif keuangan

Financial Perspective

\begin{tabular}{|c|c|c|c|}
\hline $\begin{array}{l}\text { Strategic } \\
\text { Objective }\end{array}$ & $\begin{array}{c}\text { Measurem } \\
\text { ent }\end{array}$ & Action (CSF) & IS Needs \\
\hline $\begin{array}{l}1 \text { meningkat } \\
\text { kan } \\
\text { pelayanan } \\
\text { Sistem } \\
\text { Informasi } \\
\text { yang } \\
\text { terintegras } \\
\text { i di } \\
\text { beberapa } \\
\text { unit kerja }\end{array}$ & $\begin{array}{l}\text { A. Peningkat } \\
\text { an } \\
\text { kualitas } \\
\text { layanan } \\
\text { SI } \\
\text { disetiap } \\
\text { unit kerja }\end{array}$ & $\begin{array}{l}\text { A1.Mengoptimal } \\
\text { kan LMS } \\
\text { dan jaringan } \\
\text { komunikasi } \\
\text { online } \\
\text { (berbasis } \\
\text { web) } \\
\text { A2. Membentuk } \\
\text { Tim } \\
\text { pengembang } \\
\text { an teknologi } \\
\text { informasi. } \\
\text { A3 } \\
\text { Pengembang } \\
\text { an sistem E } \\
\text { learning } \\
\text { (LMS) }\end{array}$ & $\begin{array}{l}\text { A. Aplikasi } \\
\text { LMS } \\
\text { berbasis } \\
\text { web }\end{array}$ \\
\hline $\begin{array}{l}2 \text { Mengopti } \\
\text { malkan } \\
\text { infrastrukt } \\
\text { ur } \\
\text { teknologi } \\
\text { informasi }\end{array}$ & $\begin{array}{l}\text { A. Layanan } \\
\text { TI }\end{array}$ & $\begin{array}{l}\text { A1. Mengatur } \\
\text { infrastruktur } \\
\text { sehingga } \\
\text { antara } \\
\text { penyediaan } \\
\text { dan } \\
\text { kebutuhan } \\
\text { sesuai } \\
\text { A2. Membangun } \\
\text { sumber } \\
\text { tenaga listrik } \\
\text { sendiri } \\
\text { untuk } \\
\text { menjamin } \\
\text { kelancaran } \\
\text { LMS } \\
\text { A3. } \\
\text { Mengoptima } \\
\text { lkan } \\
\text { manajemen } \\
\text { resiko } \\
\text { terhadap } \\
\text { gangguan TI }\end{array}$ & \\
\hline
\end{tabular}

Tabel 3

konsolidasi Balanced Scorecard dan Analisis Critical Succes Factor Perspektif Pelanggan

\begin{tabular}{|c|c|c|c|}
\hline \multicolumn{4}{|c|}{ Pelanggan Perspective } \\
\hline $\begin{array}{l}\text { Strategic } \\
\text { Objective }\end{array}$ & $\begin{array}{c}\text { Measure } \\
\text { ment }\end{array}$ & Action (CSF) & IS Needs \\
\hline $\begin{array}{l}\text { 1. Menamba } \\
\text { h fasilitas } \\
\text { pelayanan } \\
\text { akademik } \\
\text { dan TI }\end{array}$ & $\begin{array}{c}\text { A. Layanan } \\
\text { mahasis } \\
\text { wa }\end{array}$ & $\begin{array}{l}\text { A1.Meningkatka } \\
\text { n kinerja } \\
\text { LMS } \\
\text { A2. Menambah } \\
\text { IP Address } \\
\text { dan } \\
\text { bandwith } \\
\text { yang } \\
\text { disediakan } \\
\text { oleh } \\
\text { universitas } \\
\text { sehingga } \\
\text { akses } \\
\text { internet } \\
\text { lebih cepat } \\
\text { A3.Meningkatka } \\
\text { n fasilitas } \\
\text { online }\end{array}$ & $\begin{array}{l}\text { B. Mengad } \\
\text { akan } \\
\text { sosialisa } \\
\text { si } \\
\text { penggun } \\
\text { aan } \\
\text { LMS }\end{array}$ \\
\hline
\end{tabular}

Tabel 2 


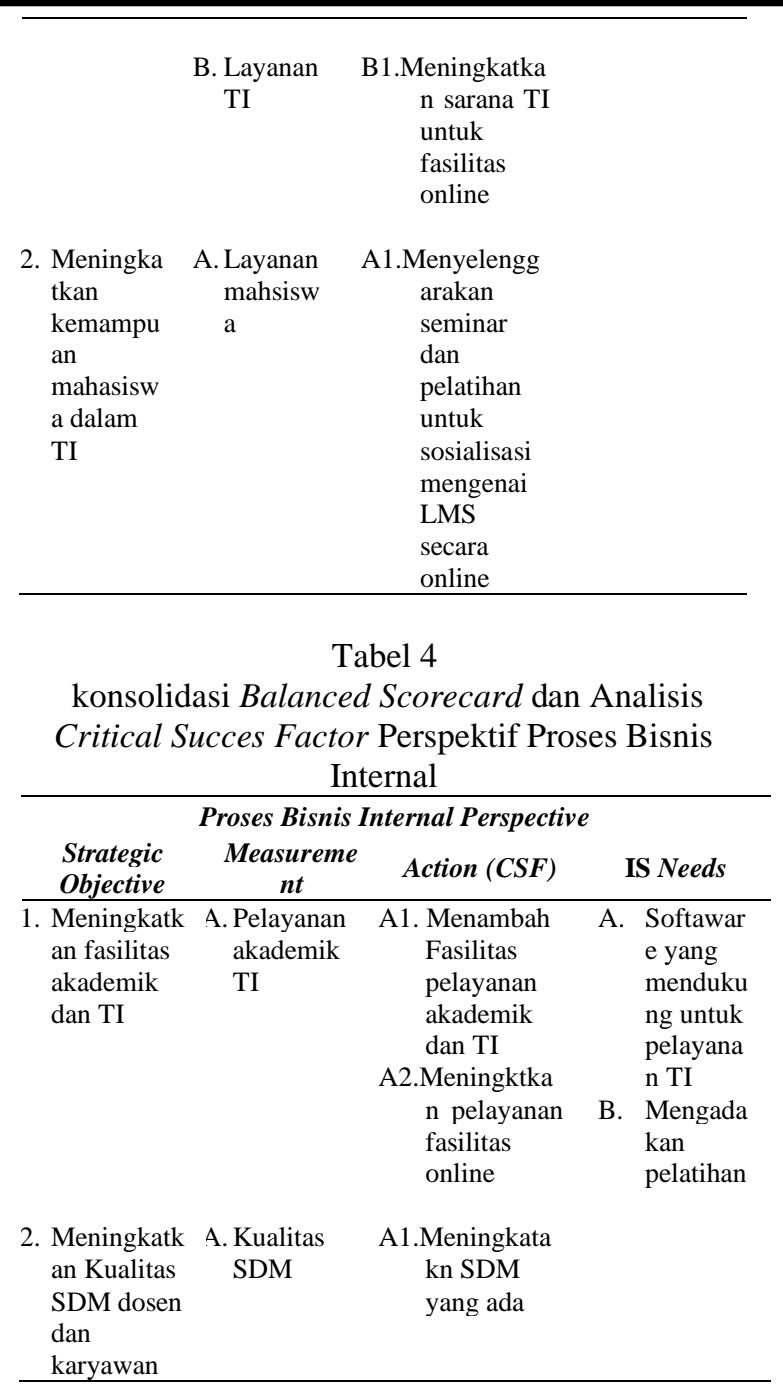

Tabel 5 konsolidasi Balanced Scorecard dan Analisis Critical Succes Factor Perspektif Inovasi dan pembelajaran

\begin{tabular}{|c|c|c|c|}
\hline \multicolumn{4}{|c|}{ Inovasi dan pembeljaran Perspective } \\
\hline $\begin{array}{l}\text { Strategic } \\
\text { Objective }\end{array}$ & $\begin{array}{c}\text { Measure } \\
\text { ment }\end{array}$ & Action (CSF) & IS Needs \\
\hline $\begin{array}{l}\text { 1. melibatkan } \\
\text { knowledge } \\
\text { manageme } \\
\text { nt untuk } \\
\text { mempertah } \\
\text { ankan } \\
\text { kelangsung } \\
\text { an hidup } \\
\text { pertumbuha } \\
\text { n } \\
\text { perusahaan }\end{array}$ & $\begin{array}{l}\text { A. transfer } \\
\text { knowledg } \\
\text { e dari } \\
\text { karyawan } \\
\text { untuk } \\
\text { organisas } \\
\text { i }\end{array}$ & $\begin{array}{l}\text { A1.Implementas } \\
\text { i } \\
\text { knowledge } \\
\text { manageme } \\
\text { nt system } \\
\text { (E- } \\
\text { Learning) } \\
\text { A2.Mendorong } \\
\text { karyawan } \\
\text { untuk } \\
\text { memelihar } \\
\text { a } \\
\text { pengetahu } \\
\text { an dalam } \\
\text { organisasi } \\
\text { dengan } \\
\text { memberik } \\
\text { an benafits } \\
\text { tertentu }\end{array}$ & 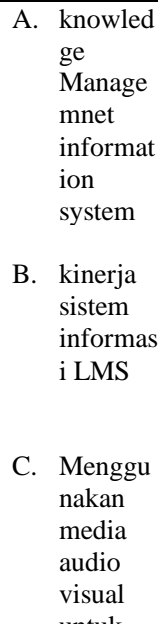 \\
\hline $\begin{array}{l}\text { 2. meningkatk } \\
\text { an akses } \\
\text { jaringan } \\
\text { dan } \\
\text { promosi } \\
\end{array}$ & $\begin{array}{l}\text { A. Meningk } \\
\text { atkan } \\
\text { kerjasam } \\
\text { a } \\
\end{array}$ & $\begin{array}{l}\text { A1.Meningkatk } \\
\text { an } \\
\text { kerjasama } \\
\text { dengan }\end{array}$ & $\begin{array}{l}\text { untuk } \\
\text { promosi }\end{array}$ \\
\hline
\end{tabular}

instansi

lain untuk

lebih

mengemba

ngkan

pertumbuh

an

B1. Menentukan

target

$\begin{array}{ll}\text { kan target } & \text { promosi } \\ \text { promosi } & \text { yang } \\ \text { dengan } & \text { fleksibel }\end{array}$

$\begin{array}{ll}\text { kan target } & \text { promosi } \\ \text { promosi } & \text { yang } \\ \text { dengan } & \text { fleksibel }\end{array}$

$\begin{array}{ll}\text { kan target } & \text { promosi } \\ \text { promosi } & \text { yang } \\ \text { dengan } & \text { fleksibel }\end{array}$

jelas B2. Melakukan

survey

terhadap

lulusan

SMU

\section{d. Sistem Informasi Learning Management System}

Berdasarkan daftar kebutuhan sistem informasi tersebut pada perencanaan Balanced Scorecard dan Analisis Critical Success Factor maka dapat di susun perencanaan pengembangan sistem informasi. Perencanan sistem informasi itu berdasarkan empat kuadran:

1) Strategic, merupakan sistem informasi yang dapat mengubah struktur maupun kinerja rantai nilai secara keseluruhan. Sistem informasi learning management system sebagai strategi promosi yang saat ini pembelajaran dulakukan di rumah, dan sebagai tempat data yang berhubungan dengan nilai, perkuliahan, data mahasiswa.

2) High Potential, merupakan sistem informasi

3) yang berimplikasi pada pasar atau jasa yang ditawarkan.tentunya LMS ini sebagai database mahasiswa dan menyimpan data mengenai proses pembalajaran yang dilakukan oleh dosen yang bersangkutan.

4) Key Operational, merupakan sistem informasi yang dibutuhkan karena akan memberi manfaat paling besar. LMS ini memiliki manfaat yang besar terutama saat ini yang perkuliahan dilakukan dengan jarak jauh, sehingga dengan adanya LMS ini mahasiswa dan dosen masih bisa melakukan interaksi melalui aplikasi tersebut. Sehingga transfer ilmu

5) tidak terhenti karena suatu kondisi darurat untuk tidak mengadakan perkuliahan di kelas.

6) Support, merupakan sistem informasi yang dibutuhkan untuk meningkatkan produktifitas. Tentuny aplikasi LMS ini di support oleh sistem Manajemn sebagai pendukung aktivitas pelayanan kepada mahasiswa dan dosen setrta karyawan.

Knowledge Management termasuk dalam kuadrat High Potential, karena implikasi pada jasa yang ditawarkan oleh Universitas $x$. Implementasi Knowledge Management menjadi topik penelitian karena melihat dengan peluang yang dapat terjadi melalui implementasi Knowledge Management 
System mempunyai potensi untuk dikembangkan ke kuadran berikutnya yaitu kuadran strategic. Perencanaan Strategy sistem informasi learning management system telah dilakukan dan dan terindifikasi adanya kebutuhan yang terus untuk meningkatkan pelayanan kepada mahsiswa dan juga dosen.

\section{Kesimpulan}

Dengan adanya pengembangan pemebelajaran menggunakan Learning Managament system ini tentunya dapat menjadi solusi terbaik saat ini, agar pembelajaran perkuliahan masih dapat dilakukan walaupun dengan jarak jauh. Tentunya semua proses pembelajaran dapat di pantau dengan baik lewat learnjng management system. Semua data yang berhungan dengan pembelajaran yaitu materi, absensi dan nilai sudah tersimpan di dalam database yang memudahkan karyawan yang berhubungan terhadap pengawasan dosen dalam memberikan perkuliahan lebih mudah.

\section{Daftar Rujukan}

[1] Wahyu Nurjaya WK, Model Strategic Planning For Information System Menggunakan
Balanced Scorecard Pada Universitas Komputer Indonesia Bandung. Bandung.

[2] Ward, J., and Peppard, J. Strategic Planning for Information Systems. 3th Edition. John Wiley \& Sons, Ltd., USA. 2003.

[3] Indrajit, Richardus Eko. Dan Djokopranoto, R. Strategi Manajemen Perguruan Tinggi. Jakarta: Elex Media Komputindo, 2003.

[4] Galliers, R.D., Leidner, D.E., Strategic Information Managemen, Elsivier ButterworthHeineman, Burlington, 2003.

[5] David Fred R., Manajemen Strategis Kon-sep. Edisi Ketujuh, PT Intan Sejati Klaten, 2004.

[6] Kadir, A. Pengenalan Sistem Informasi. Andi Offset, Yogyakarta. 2003.

[7] Dewi Mustari, 10:41 (27 juli 2011), http://riezqa.blogspot.com/2007/08 /knowledge-management.html, 2011, Jakarta.

[8] Peter Gottschalk, Strategic Knowledge Management Technology, Idea Group Publishing, Hersey, 2005.

[9] A.Pearce, John dan Robinson,Jr., Richard B. Manajemen Strategis - Formulasi, Implementasi, dan Pengendalian. Edisi 12. Salemba Empat: Jakara, 2014.

[10] Debowski, S. Knowledge Management. Singapore: Seng Lee Press Pte Ltd. 2006 